\title{
AN APPLICATION OF GIBBONS- ROSS-SHANKEN'S TEST OF THE EFFICIENCY OF A GIVEN PORTFOLIO
}

\author{
Eneas A. Caldiño García*
}

Centro de Estudios Económicos, El Colegio de México A. C.

(Received 4 November 2003, accepted 10 February 2004)

\begin{abstract}
This paper provides an adaptation of the statistical tests of Gibbons, Ross, and Shanken (1989) to test for portfolio efficiency in two cases where theirs can not directly be used: 1) When the portfolio whose efficiency is being tested is not included in the set of securities generating the mean-standard deviation frontier and, 2) When testing for the existence of an efficient portfolio (of a given set of $\mathrm{L}$ portfolios) when none of these $\mathrm{L}$ portfolios is included in the set of securities generating the mean-standard deviation frontier. Our tests can be used to determine the efficiency of a variety of mutual funds
\end{abstract}

\section{Resumen}

En este artículo se adaptan las pruebas estadísticas de Gibbons, Ross, y Shanken (1989) para probar la eficiencia de un portafolio en dos casos en los que sus pruebas no pueden usarse directamente: 1) Cuando el portafolio cuya eficiencia está siendo probada no está incluído en el conjunto de instrumentos financieros que generan la frontera de media-desviación estándard $y, 2$ ) Cuando se prueba la existencia de un portafolio eficiente (de un conjunto dado de L portafolios), cuando ninguno de estos $L$ portafolios está incluído en el conjunto de instrumentos financieros que generan la frontera de media-desviación estándard. Nuestros estadísticos pueden usarse para probar la eficiencia de fondos de inversión.

JEL classification: G11, G14

Keywords: Portfolio Choice, Information and Market Efficiency

* Centro de Estudios Económicos, El Colegio de México, A. C., Camino al Ajusco 20, Col. Pedregal de Sta. Teresa, Deleg. Tlalpan, 10740, México, D. F., Telephone: (52)5449-3000 ext. 4160, E-mail: eneas@colmex.mx

The author wishes to thank Terry F. Bohn for her helpful comments. 


\section{Introduction}

In this paper we adapt the statistical tests of Gibbons, Ross, and Shanken (1989) using the multivariate regression approach to test: i) Whether a given portfolio of $\mathrm{N}+1$ securities is efficient with respect to this set of $\mathrm{N}+1$ securities (in contrast to $G-R-S^{\prime} s$ case, this set does not include the portfolio whose efficiency is being tested), and, ii) Whether there exists a portfolio of a given set of $\mathrm{L}$ portfolios of $\mathrm{N}+1$ securities, $(\mathrm{L}<\mathrm{N})$, that is efficient with respect to the set of $\mathrm{N}+1$ securities (in contrast to $G-R-S^{\prime} s$ case, this set of $\mathrm{N}+1$ securities does not include the $\mathrm{L}$ portfolios of whom the existence of an efficient portfolio is being tested).

Gibbons, Ross, and Shanken (1989) (see also MacKinlay (1987)) propose a test to determine "whether any particular portfolio is $e x$-ante mean-variance efficient", i.e. whether any particular portfolio is ex -ante on the meanstandard deviation frontier. They work with $\mathrm{N}+2$ securities or portfolios: a riskless security with return $R_{0}, \mathrm{~N}$ linearly independent risky securities with returns $R_{1}, R_{2}, \cdots, R_{\mathrm{N}}$ and a portfolio $p$, whose efficiency is being tested, with return $R_{p}$. Portfolio $p$ is not a portfolio of the first $\mathrm{N}+1$ securities, i.e. $R_{p}$ is not a weighted average of the returns $R_{0}, R_{1}, \cdots, R_{\mathrm{N}}$. Their test is aimed at testing whether portfolio $p$ is on the frontier generated by the $\mathrm{N}+1$ securities with returns $R_{0}, R_{1}, \cdots, R_{\mathrm{N}}$, and portfolio $p$, itself. This statistical test has frequently been used in testing the CAPM.

In Section 2 we work with $\mathrm{N}+2$ securities or portfolios: the $\mathrm{N}+1$ securities with returns $R_{0}, R_{1}, \cdots, R_{\mathrm{N}}$ and a portfolio $q$, whose efficiency is being tested, with return $R_{q}=\sum_{i=0}^{\mathrm{N}} \alpha_{i} R_{i}$, where $\sum_{i=0}^{\mathrm{N}} \alpha_{i}=1$, (i.e. In our case, portfolio $q$ is a portfolio of the first $\mathrm{N}+1$ securities). The first of our objectives is to use $G-R-S^{\prime} s$ statistical test to derive a corresponding statistical test to determine whether portfolio $q$ is on the mean-standard deviation frontier generated by the $\mathrm{N}+1$ securities with returns $R_{0}, R_{1}, \cdots, R_{\mathrm{N}}$. This adapted version of the $G-R-S^{\prime} s$ test can be used directly when testing whether a given portfolio of a set of securities is efficient with respect to this set of securities. $G-R-S^{\prime} s$ test can not be applied directly in this case.

In Section 7 of Gibbons, Ross, and Shanken (1989), they propose a test to determine whether there exists a portfolio of a given set of $\mathrm{L}$ portfolios that is ex-ante mean-variance efficient, i.e. whether there exists a portfolio of a given set of $\mathrm{L}$ portfolios that is ex-ante on the mean-standard deviation frontier. They work with $\mathrm{N}+\mathrm{L}+1$ securities or portfolios: a riskless security with return $R_{0}, \mathrm{~N}$ linearly independent securities with returns $R_{1}, R_{2}, \cdots, R_{\mathrm{N}}$ and L linearly independent portfolios $p_{1}, p_{2}, \cdots, p_{\mathrm{L}}$, with returns $R_{p 1}, R_{p 2}, \cdots, R_{p \mathrm{~L}}$. None of these $\mathrm{L}$ portfolios is a portfolio of the first $\mathrm{N}+1$ securities, i.e. for all $k \in\{1,2, \cdots, \mathrm{L}\}$, $R_{p k}$ is not a weighted average of the returns $R_{0}, R_{1}, \cdots, R_{N}$. Their test is aimed at testing whether there exists a portfolio of the $\mathrm{L}$ portfolios $p_{1}, p_{2}, \cdots, p_{\mathrm{L}}$ on the frontier generated by the $\mathrm{N}+1$ securities with returns $R_{0}, R_{1}, \cdots, R_{\mathrm{N}}$ and portfolios $p_{1}, p_{2} \cdots, p_{\mathrm{L}}$, themselves. Their statistical test has been frequently used in testing some versions of the Arbitrage Pricing Theory, APT, in which the pricing restriction can be restated as "a linear combination of factor portfolios is mean-variance efficient" (Chamberlain (1983), Grinblatt and Titman (1987), Connor and Korajczyk (1988, 1995), Lehmann and Modest (1988), etc.).

In Section 3 we work with $\mathrm{N}-\mathrm{L}+1$ securities or portfolios: the $\mathrm{N}+1$ securi- 
ties with returns $R_{0}, R_{1}, R_{2}, \cdots, R_{\mathrm{N}}$ plus $\mathrm{L}(\mathrm{L} \leq \mathrm{N})$, linearly independent portfolios $q_{1}, q_{2}, \cdots, q_{\mathrm{L}}$, with returns $R_{q 1}, R_{q 2}, \cdots, R_{q \mathrm{~L}}$, where $R_{q k}=\sum_{i=0}^{N} \alpha_{i}^{k} R_{i}$ and $\sum_{i=0}^{N} \alpha_{i}^{k}=1$, for $k=1,2, \cdots, \mathrm{L}$ (in our case, these $\mathrm{L}$ portfolios are portfolios of the first $\mathrm{N}+1$ securities). The second of our objectives is to 11se $G-R-S^{\prime} s$ statistical test to derive a corresponding statistical test to determine whether there exists a portfolio of portfolios $q_{1}, q_{2}, \cdots, q_{\mathrm{L}}$ that is on the mean-standard deviation frontier generated by the $\mathrm{N}+1$ securities with returns $R_{0}, R_{1}, \cdots, R_{\mathrm{N}}$. Our adapted version of $G-R-S^{\prime} s$ statistical test can be used directly when testing if there exists a portfolio of a given set of portfolios that is efficient with respect to the set of securities included in the portfolios. $G-R-S^{\prime} s$ test can not be applied directly in this case.

In Section 4 we mention cases in which the statistical tests presented here can be useful when testing the efficiency of a portfolio. In Section 5 we summarize the results.

\section{Testing the Efficiency of a Portafolio}

Given a set $\mathcal{S}$ of $K$ securities $(K \geq 1)$ a portfolio of these securities with expected return equal to $\mathrm{E} \in \mathbb{R}$, is the frontier portfolio with expected return $\mathrm{E}$ if its return has the minimum variance among returns of portfolios (of securities in $S$ ) that have expected return E (see Constantinides and Malliaris (1995)). A frontier portfolio is also known as a mean-variance efficient portfolio. In case the frontier portfolio exists for $\mathrm{E} \in \mathbb{R}$, let $\sigma(\mathrm{E})$ be its standard-deviation. The mean-standard deviation frontier generated by the $K$ securities in $\mathcal{S}$ is the set:

$$
M S F \equiv\left\{(\sigma(\mathrm{E}), \mathrm{E}) \in \mathbb{R}^{2} \mid \sigma(\mathrm{E}) \text { exists for } \mathrm{E} \in \mathbb{R}\right\} .
$$

Gibbons, Ross, and Shanken (1989) consider a given portfolio $p$ which is not a portfolio of the riskless security with return $R_{0}$ and the $\mathrm{N}$ linearly independent securities with returns $R_{1}, \cdots, R_{\mathrm{N}}$. They propose a test to determine whether portfolio $p$ is in the frontier generated by the securities with returns $R_{0}, R_{1}, \cdots, R_{N}$, and portfolio $p$, itself. Here we consider a given portfolio $q$ which is a portfolio of the $\mathrm{N}+1$ securities with returns $R_{0}, R_{1}, \cdots, R_{\mathrm{N}}$. We use their test to generate a corresponding test to determine whether portfolio $q$ is in the frontier generated by the securities with returns $R_{0}, R_{1}, \cdots, R_{\mathrm{N}}$.

To be able to apply $G-R-S^{\prime} s$ test we need a way to go from their case to ours. This can be done using the following well known observation that states that repackaging the securities does not alter the mean-standard deviation frontier:

Lemma 1. The mean-standard deviation frontier generated by a set of M linearly independent securities is equal to the mean-standard deviation frontier generated by any $\mathrm{M}$ linearly independent portfolios of the $\mathrm{M}$ linearly independent securities.

$\mathrm{Dm}$. Let $R_{x}$ denote the M-dimensional vector of returns of $\mathrm{M}$ linearly independent securities, and $\mathrm{E}\left(R_{x}\right)$ be the corresponding vector of expected returns. Let $R_{y}$ denote the M-dimensional vector of returns of $\mathrm{M}$ linearly independent portfolios of the $\mathrm{M}$ securities, and $\mathrm{E}\left(R_{y}\right)$ be the corresponding vector of expected returns. Then, $R_{y}=\Gamma^{\prime} R_{x}$, where $\Gamma$ is an invertible $\mathrm{M} \times \mathrm{M}$ matrix such that $\Gamma^{\prime} 1_{\mathrm{M}}=1_{\mathrm{M}}$, where $1_{\mathrm{M}}$ is the M-dimensional vector of ones. 
Let $\sigma_{x}(\mathrm{E})$ be the standard deviation of the return of the frontier portfolio of the $\mathrm{M}$ securities with expected return $\mathrm{E} \in \mathbb{R}$, and $\sigma_{y}(\mathrm{E})$ be the standard deviation of the return of the frontier portfolio of the $M$ portfolios with expected return $\mathrm{E} \in \mathbb{R}$. This means:

$$
\begin{gathered}
\sigma_{x}(\mathrm{E}) \equiv \min _{\omega \in \mathbb{R}^{\mathrm{M}}} \operatorname{var}\left(\omega^{\prime} R_{x}\right) \\
\text { s.t. } \omega^{\prime} 1_{\mathrm{M}}=1 \text { and } \quad \omega^{\prime} \mathrm{E}\left(R_{x}\right)=\mathrm{E},
\end{gathered}
$$

and

$$
\begin{gathered}
\sigma_{y}(\mathrm{E})=\min _{\alpha \in \mathbb{R}^{\mathrm{M}}} \operatorname{var}\left(\alpha^{\prime} \Gamma^{\prime} R_{x}\right) \\
\text { s.t. } \quad \alpha^{\prime} 1_{\mathrm{M}}=1 \quad \text { and } \quad \alpha^{\prime} \mathrm{E}\left(\Gamma^{\prime} R_{x}\right)=\mathrm{E} .
\end{gathered}
$$

It has to be shown that for $\mathrm{E} \in \mathbb{R}, \sigma_{x}(\mathrm{E})=\sigma_{\mathrm{y}}(\mathrm{E})$. If $\omega^{*}$ solves minimization problem (2), then $\alpha^{*}=\Gamma^{-1} \omega^{*}$ solves minimization problem (4). Otherwise, there exists $\alpha \in \mathbb{R}^{\mathrm{M}}$ satisfying (5) such that $\operatorname{var}\left(\alpha^{\prime} \Gamma^{\prime} R_{x}\right)<\operatorname{var}\left(\alpha^{*^{\prime}} \Gamma^{\prime} R_{x}\right)=$ $\operatorname{var}\left(\omega^{*^{\prime}} R_{x}\right)$ Then, $\omega \equiv \Gamma \alpha$ satisfies $(3)$ and $\operatorname{var}\left(\omega^{\prime} R_{x}\right)<\operatorname{var}\left(\omega^{*^{\prime}} R_{x}\right)$, which contradicts the fact that $\omega^{*}$ solves problem (2). Hence, $\alpha^{*}=\Gamma^{-1} \omega^{*}$ solves minimization problem (4). Hence,

$$
\sigma_{y}(\mathrm{E})=\operatorname{var}\left(\alpha^{*^{\prime}} \Gamma^{\prime} R_{x}\right)=\operatorname{var}\left(\omega^{*^{\prime}} \Gamma^{\prime}-1\right.
$$

Next, we apply Lemma 1 to our case. Portfolio $q$ has return $R_{q}=\sum_{i=0}^{\mathrm{N}} \omega_{i} R_{i}$, where $\sum_{i=0}^{\mathrm{N}}=1$. Without loss of generality, $\omega_{1} \neq 0$. Let $R_{x} \equiv\left(R_{0}, R_{1}, \cdots R_{\mathrm{N}}\right)^{\prime}$, $\Gamma \equiv\left(\begin{array}{llllll}e_{1} & \omega_{q} & e_{3} & e_{4} & \cdots & e_{\mathrm{N}+1}\end{array}\right)$, where $e_{i}$ is the $(\mathrm{N}+1)$ dimensional vector with 1 in the $i$-th row and zero elsewhere, $i=1,3,4, \cdots, \mathrm{N}+1, \omega_{q} \equiv\left(\omega_{0} \omega_{1} \cdots \omega_{\mathrm{N}}\right)^{\prime}$, and $R_{y} \equiv \Gamma^{\prime} R_{x}=\left(\begin{array}{llll}R_{0} & R_{q} & R_{2} \cdots R_{\mathrm{N}}\end{array}\right)^{\prime}, \operatorname{Det}(\Gamma)=\omega_{1} \neq 0$. By Lemma 1, our hypothesis:

$\mathrm{H}_{0}$ : "Portfolio $q$ is on the mean-standard deviation frontier generated by the

$\mathrm{N}+1$ securities with returns $R_{0}, R_{1}, R_{2}, \cdots, R_{\mathrm{N}}$ " is equivalent to the hypothesis:

$\mathrm{H}_{0}^{\prime}$ : "Portfolio $q$ is on the mean-standard deviation frontier generated by the $\mathrm{N}$ securities with returns $R_{0}, R_{2}, R_{3}, \cdots, R_{\mathrm{N}}$, and portfolio $q$, itself."

With this, the hypothesis we want to test is in $G-R-S^{\prime} s$ frame and we can apply their test adapted as follows:

Following Gibbons, Ross and Shanken (1989), it is assumed we have data from $T$ periods. Let $r_{q t}$ be the excess return of portfolio $q$ over the return of the riskless security on period $t\left(r_{q t} \equiv R_{q t}-R_{0 t}\right)$; let $r_{t}$ be the $(\mathrm{N}-1)$-dimensional vector of excess returns of securities 2 through $\mathrm{N}$ over the return of the riskless security on period $t\left(r_{t} \equiv\left(\begin{array}{lll}R_{2 t}-R_{0 t} & \left.R_{3 t}-R_{0 t} \cdots R_{\mathrm{N} t}-R_{0 t}\right)^{\prime}\end{array}\right)\right.$.

Consider the multivariate linear regression:

$$
r_{t}=\alpha+\mathrm{b} r_{q t}+\varepsilon_{t} \quad t=1,2, \cdots, T
$$

where

$$
\mathrm{E}\left(\varepsilon_{t}\right)=0, \quad \mathrm{E}\left(\varepsilon_{t} r_{q t}\right)=0, \quad \alpha \in \mathbb{R}^{\mathrm{N}-1}, \quad \mathrm{~b} \in \mathbb{R}^{\mathrm{N}-1} .
$$


It is assumed that $\left\{\left(\begin{array}{ll}r_{t}^{\prime} & r_{q t}\end{array}\right)\right\}_{t=1}^{T}$ are independent and identically distributed multinormal $\mathrm{N}$-dimensional random vectors. This implies $\varepsilon_{1}, \varepsilon_{2}, \cdots, \varepsilon_{T}$ are independent and identically distributed $N_{\mathrm{N}-1}\left(0, \Sigma_{\varepsilon}\right)$ random vectors and $\varepsilon_{t}$ is statistically independent of $r_{q t}$, for $t=1,2, \cdots, T$. (Muirhead (1982)).

Let $\hat{\alpha}$ and $\hat{b}$ the OLS estimators of $\alpha$ and $b$.

$$
\begin{gathered}
\hat{\Sigma}_{\varepsilon}^{u} \equiv \frac{1}{T-2} \sum_{t=1}^{T}\left[r_{t}-\hat{\alpha}-\hat{\mathrm{b}} r_{q t}\right]\left[r_{t}-\hat{\alpha}-\hat{\mathrm{b}} r_{q t}\right]^{\prime}, \\
\hat{\Sigma}_{\varepsilon}^{\mathrm{MLE}} \equiv \frac{T-2}{T} \hat{\Sigma}_{\varepsilon^{*}}^{u}
\end{gathered}
$$

(i.e. $\hat{\Sigma}_{\varepsilon}^{u}$ is the unbaised estimator of $\Sigma_{\varepsilon}$ and $\hat{\Sigma}_{\varepsilon}^{\mathrm{MLE}}$ is the maximum likelihood estimator of $\Sigma_{\varepsilon}$. N $\leq T-1$ so that $\hat{\Sigma}_{\varepsilon}^{u}$ is nonsingular).

$$
\begin{gathered}
\bar{r}_{q} \equiv \frac{1}{T} \sum_{t=1}^{T} r_{q t}, \\
\hat{\sigma}_{q}^{2} \equiv \frac{1}{T} \sum_{t=1}^{T}\left(r_{q t}-\bar{r}_{q}\right)^{2}, \\
\hat{\mathcal{S}}_{q}^{2} \equiv \bar{r}_{q}^{2} / \hat{\sigma}_{q}^{2} .
\end{gathered}
$$

Applying Gibbons, Ross \& Shanken (1989), we get the following: Proposition 1. The smali-sample conditional distribution of

$$
\frac{T(T-\mathrm{N})}{(\mathrm{N}-1)(T-2)} \cdot \frac{\hat{\alpha}^{\prime} \hat{\Sigma}_{\varepsilon}^{u-1} \hat{\alpha}}{1+\hat{\mathcal{S}}_{q}^{2}}=\frac{T-\mathrm{N}}{\mathrm{N}-1} \cdot \frac{\hat{\alpha}^{\prime} \hat{\Sigma}_{\varepsilon}^{\mathrm{MLE}-1} \hat{\alpha}}{1+\hat{\mathcal{S}}_{q}^{2}},
$$

given $r_{q}$, is non-central $F_{\mathrm{N}-1, T-\mathrm{N}}(\lambda)$, where

$$
\lambda \equiv T \cdot \frac{\alpha^{\prime} \Sigma_{\varepsilon}^{-1} \alpha}{1+\hat{S}_{q}^{2}}
$$

Under the hypothesis $\mathrm{H}_{0}$, the parameter $\lambda$ is equal to zero (because $\alpha=0$ ) and the statistic (11) has central $F_{\mathrm{N}-1, T-\mathrm{N}}$ distribution (uncondicionally). Given the observations $\left\{\left(r_{t}^{\prime} r_{q t}\right)\right\}_{t=1}^{T}$, the hypotesis $\mathrm{H}_{0}$ is rejected if the statistic (11) is significantly different from zero.

$G-R-S^{\prime} s$ geometrical interpretation of their test is preserved: $\alpha^{\prime} \sum_{\varepsilon}^{-1} \alpha=$ $\mathcal{S}^{2}-\mathcal{S}_{q}^{2}$, where this time, $\mathcal{S}$ is the slope of the frontier generated by the securities with returns $R_{0}, R_{2}, R_{3}, \cdots, R_{\mathrm{N}}$, and portfolio $q$, and $\mathcal{S}_{q}=\mathrm{E}\left(r_{q}\right) /\left(\operatorname{var}\left(r_{q}\right)\right)^{1 / 2}$. By Lemma 1 above and the fact that $\alpha^{\prime} \sum_{\varepsilon}^{-1} \alpha=\mathcal{S}^{2}-\mathcal{S}_{q}^{2}$, the statistical test presented in Proposition 1 is not affected by wich of the risky securities 
is labeled as the security with return " $R_{1}$ ", as long as this one is included in portfolio $q$ (i.e. $\left.\omega_{1} \neq 0\right)$.

\section{Testing the Efficiency of a Portafolio of L Portfolios}

Gibbons, Ross and Shanken (1989) also consider a given set of $L \geq 1$ linearly independent portofolios $p_{1}, p_{2}, \cdots, p_{\mathrm{L}}$, none of wich is a portfolio of the securities with returns $R_{0}, R_{1}, \cdots, R_{\mathrm{N}}$. They propose a test to determine wether there exists a portfolio of these $\mathrm{L}$ portfolios in the frontier genereted by the securities with returns $R_{0}, R_{1}, \cdots, R_{\mathrm{N}}$ and portfolios $p_{1}, p_{2}, \cdots, p_{\mathrm{L}}$, themselves. Here we consider a given set of $1 \leq \mathrm{L} \leq \mathrm{N}$ linearly independenyt portfolios $q_{1}, q_{2}, \cdots, q_{\mathrm{L}}$, where each of them is a portfolio of the $\mathrm{N}+1$ securities with returns $R_{0}, R_{1}, \cdots, R_{\mathrm{N}}$. We use their test to generate a corresponding test to determine whether there exist a portfolio of the L portfolios $q_{1}, q_{2}, \cdots, q_{\mathrm{L}}$ in the frontier generated by the securities with returns $R_{0}, R_{1}, \cdots, R_{\mathrm{N}}$.

We proceed by applying Lemma 1 to our case. For $\mathrm{K}=1,2, \cdots, \mathrm{L}$, portfolio $q_{k}$ has return $R_{q_{k}}=\sum_{i=0}^{N} \omega_{i}^{k} R_{i}$, where $\sum_{i=0}^{N} \omega_{i}^{k}=1$. Let us assume that $\omega_{k}^{k} \neq 0$. (i. e. that security " $\mathrm{k}$ " is included in portfolio $q_{k}, \mathrm{~K}=1,2, \cdots, \mathrm{L}$ ). Let $R_{x} \equiv\left(R_{0}, R_{1}, \cdots, R_{\mathrm{N}}\right)^{\prime}, \quad \Gamma \equiv\left(\begin{array}{lllll}e_{1} & \omega_{q_{1}} & \omega_{q_{2}} \cdots \omega_{q_{\mathrm{L}}} & e_{\mathrm{L}+2} & e_{\mathrm{L}+3} \cdots e_{\mathrm{N}+1}\end{array}\right)$, where $e_{i}$ is the $(\mathrm{N}+1)$ dimensional vector with 1 in the $i-t h$. row and zero

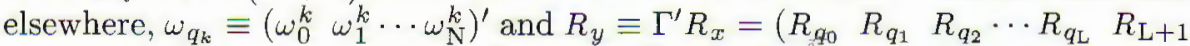
$\left.R_{\mathrm{L}+2} \cdots R_{\mathrm{N}}\right)^{\prime}$. Det $(\Gamma)=\omega_{1}^{1} \times \omega_{2}^{2} \times \cdots \times \omega_{\mathrm{L}}^{\mathrm{L}} \neq 0$. By Lemma 1, the hypothesis: $\mathrm{H}_{L}$ : "There exists a portfolio of the $\mathrm{L}$ portfolios $q_{1}, q_{2}, \cdots, q_{\mathrm{L}}$ in the meanstandard deviation frontier geneated by the $\mathrm{N}+1$ securities with returns $R_{0}, R_{1}, \cdots, R_{\mathrm{N}} "$

is equivalent to the hypothesis:

$\mathrm{H}_{L}^{\prime}$ : "There exists a portfolio of the $\mathrm{L}$ portfolios $q_{1}, q_{2}, \cdots, q_{\mathrm{L}}$ in the meanstandard deviation frontier generated by the $\mathrm{N}-\mathrm{L}+1$ securities with returns $R_{0}, R_{\mathrm{L}+1}, R_{\mathrm{L}+2}, \cdots, R_{\mathrm{N}}$, and the $\mathrm{L}$ portfolios $q_{1}, q_{2}, \cdots, q_{\mathrm{L}}$, themselves".

With this, the hypothesis we want to test is in the $G-R-S^{\prime}$ frame and we can apply their test.

Following Gibbons, Ross, and Shanken (1989), and Shanken (1986), let $r_{q t}$ be the L-dimensional vector of excess returns of portfolios $q_{1}, q_{2}, \cdots, q_{\mathrm{L}}$ over the return of the riskless security on period $t\left(r_{q t} \equiv\left(R_{q 1 t}-R_{0 t} R_{q 2 t}-\right.\right.$ $\left.\left.R_{0 t} \cdots R_{q \mathrm{~L} t}-R_{0 t}\right)^{\prime}\right)$; and $\rho_{t}$ be the (N-L) dimensional vector of excess returns of securities $\mathrm{L}+1$ through $\mathrm{N}$ over the return of the riskless security on period $t\left(\rho_{t} \equiv\left(R_{\mathrm{L}+1, t}-R_{0 t} \quad R_{\mathrm{L}+2, t}-R_{0 t} \cdots R_{\mathrm{N}, t}-R_{0, t}\right)^{\prime}\right)$.

Consider the multivariate linear regression:

$$
\rho_{t}=\delta+\mathrm{B} r_{q t}+e_{t} \quad t=0,1,2, \cdots, T
$$

where $\delta \in \mathbb{R}^{\mathrm{N}-\mathrm{L}}, \mathrm{B}$ is a $(\mathrm{N}-\mathrm{L}) \times \mathrm{L}$ matrix, $\mathrm{E}\left(e_{t}\right)=0$ and $\mathrm{E}\left(e_{t} T_{q t}^{\prime}\right)=0$. It is assumed that $\left\{\left(\rho_{t}^{\prime} r_{q t}\right)\right\}_{t=1}^{T}$ are independent and identically distributed multinormal $\mathrm{N}$-dimensional random vectors. This implies $e_{1}, e_{2}, \cdots, e_{T}$ are independent and identically distributed $N_{\mathrm{N}-\mathrm{L}}\left(0, \Sigma_{e}\right)$ random vectors and $e_{t}$ is statistically independent of $r_{q t}$ for $t=1,2, \cdots, T$ (Muirhead (1982)). 
Let $\hat{\delta}$ and $\hat{\mathrm{B}}$ the OLS estimators of $\delta$ and $\mathrm{B}$

$$
\begin{gathered}
\hat{\Sigma}_{e}^{u} \equiv \frac{1}{T-(\mathrm{L}+1)} \sum_{t-1}^{T}\left[r_{t}-\hat{\delta}-\hat{\mathrm{B}} r_{q t}\right]\left[r_{t}-\hat{\delta}-\hat{\mathrm{B}} r_{q t}\right]^{\prime}, \\
\hat{\Sigma}_{e}^{\mathrm{MLE}} \equiv \frac{T-(\mathrm{L}+1)}{T} \hat{\Sigma}_{e}^{u} .
\end{gathered}
$$

(i. e. $\hat{\Sigma}_{e}^{u}$ is the unbiased estimator of $\Sigma_{e}$ and $\hat{\Sigma}_{e}^{\mathrm{MLE}}$ is the maximum likelihood estimator of $\Sigma_{e}$ ).

$$
\begin{gathered}
\bar{r}_{q} \equiv \frac{1}{T} \sum_{t=1}^{T} r_{q t}, \\
\hat{\Sigma}_{q} \equiv \frac{1}{T} \sum_{t=1}^{T}\left(r_{q t}-\bar{r}_{q}\right)\left(r_{q t}-\bar{r}_{q}\right)^{\prime}, \\
\hat{\theta}_{q}^{2} \equiv \bar{r}_{q}^{\prime} \hat{\Sigma}_{q}^{-1} \bar{r}_{q} .
\end{gathered}
$$

Applying Gibbons, Ross, and Shanken (1989), we get the following:

Proposition 2. The small-sample conditional dsitribution of

$$
\frac{T(T-\mathrm{N})}{(\mathrm{N}-\mathrm{L})(T-\mathrm{L}-1)} \cdot \frac{\hat{\delta}^{\prime} \hat{\Sigma}_{\varepsilon}^{u^{-1}} \hat{\delta}}{1+\hat{\theta}_{q}^{2}}=\frac{T-\mathrm{N}}{\mathrm{N}-\mathrm{L}} \cdot \frac{\hat{\delta}^{\prime} \hat{\Sigma}_{\varepsilon}^{M L E^{-1}} \hat{\delta}}{1+\hat{\theta}_{q}^{2}},
$$

given $r_{q}$, is non-central $F_{\mathrm{N}-\mathrm{L}, T-\mathrm{N}}(\lambda)$, where

$$
\lambda \equiv T \cdot \frac{\delta^{\prime} \Sigma_{e}^{-1} \delta}{1+\hat{\theta}_{q}^{2}}
$$

Under the hypothesis $\mathrm{H}_{\mathrm{L}}$, the parameter $\lambda$ is equal to zero (because $\delta=0$ ) and the statistic (18) has a central $F_{\mathrm{N}-\mathrm{L}, T-\mathrm{N}}$ distribution (unconditionally). Given the observations $\left\{\left(r_{t}^{\prime} r_{q t}\right)\right\}_{t=1}^{T}$ the hypotesisi $\mathrm{H}_{\mathrm{L}}$ is rejected if the statistic (18) is significantly different from zero.

The geometrical interpretation of the test is as follows: $\delta^{\prime} \Sigma_{\varepsilon}^{-1} \delta=\mathcal{S}^{2}-\mathcal{S}_{\mathrm{L}}^{2}$, where $\mathrm{S}$ is the slope of the frontier generated by the securities with returns $R_{0}, R_{\mathrm{L}-1}, R_{\mathrm{L}+2}, \cdots, R_{\mathrm{N}}$, and the portfolios $q_{1}, q_{2}, \cdots, q_{\mathrm{L}}$, and $\mathcal{S}_{\mathrm{L}}$ is the slope of the frontier generated by $R_{0}$ and the portfolios $q_{1}, q_{2}, \cdots, q_{\mathrm{L}}$.

By Lemma 1 above and the fact that $\delta^{\prime} \Sigma_{\varepsilon}^{-1} \delta=\mathcal{S}^{2}-\mathcal{S}_{\mathrm{L}}^{2}$, the statistical test presented in Proposition 2 is not affected by which of the risky securities are labeled as securities with returns " $R_{1}$ ", " $R_{2}$ ",, , " $R_{\mathrm{L}}$ ", as long as the security with return " $R_{k}$ " is included in portfolio $q_{k}$, for $k=1,2, \cdots, \mathrm{L}\left(i . \quad\right.$ e. $\omega_{k}^{k} \neq$ $0, k=1,2, \cdots, \mathrm{L})$. 


\section{Applications}

Our statistical tests presented above have very practical applications. The test in Proposition 1 can be used to determine if a given portfolio of a set of $\mathrm{N}$ securities is efficient with respect to this set of $\mathrm{N}$ securities. This can be applied in the cases of a mutual fund, a money market fund, an index fund, etc. Given data on the returns of a fund and of its underlying securities, we can test for the efficiency of the fund with respect to its set of underlying securities.

The statistical test presented in Proposition 2, above, can be applied to test for the existence of a portfolio of a given set of $\mathrm{L}$ portfolios that is efficient with respect to the set of securities included in the $\mathrm{L}$ portfolios. Given data on the returns of a set of mutual funds, money market funds, index funds, etc. and the returns of their underlying securities, we can therefore test for the existence of an efficient portfolio of the funds with respect to the whole set of underlying securities.

\section{Summary}

The statistical tests of Gibbons, Ross, and Shanken (1989) are used to determine whether a given security or portfolio is efficient with respect to a set of linearly independent securities that includes the security or portfolio whose efficiency is being tested, and to determine whether there exists a portfolio of a given set of $\mathrm{L}$ portfolios that is efficient with respect to a set of linearly independent securities that includes the set of L portfolios. In this paper we use their tests to generate two corresponding statistical tests to determine whether a given portfolio of $\mathrm{N}$ securities is efficient with respect to the set of $\mathrm{N}$ securities and whether there exists a portfolio of a given set of $\mathrm{L}$ portfolios of $\mathrm{N}$ securities $(\mathrm{L}<\mathrm{N})$ that is efficient with respect to the set of $\mathrm{N}$ securities. We replace one of the securities ( $\mathrm{L}$ of the securities) generating the mean-standard frontier from the multivariate regression with the portfolio ( $\mathrm{L}$ portfolios) under consideration to obtain the adapted tests.

Our tests can then be applied to test the efficiency of a mutual fund with respect to its set of underlying securities or to test for the existence of an efficient portfolio of mutual funds with respect to their whole set of underlying securities.

\section{References}

Chamberlain, G. (1983). Funds, Factors and Diversification in Arbitrage Pricing Models. Econometrica, 51, pp. 1305-1323

Connor, G. and R. A. Korajczyk (1988). Risk and Return in an Equilibrium APT, Application of a New Test Methodology. Journal of Financial Economics, 21, pp. 255-289.

Connor, G. and R. A. Korajczyk (1995). The Arbitrage Pricing Theory and Multifactor Models of Asset Returns. In R. Jarrow, V. Maksimovic, and W.Ziemba (Eds.): Finance, in G. Nemhauser and A. R. Kan (Eds.). Handbook in Operations Research and Management Science. Vol. 9. Elsevier Science B. V., Amsterdam.

Constantinides, G. M. and A. Malliaris (1995). Portfolio Theory. In R. Jarrow, V. Maksimovic, and W.Ziemba (Eds.): Finance, in G. Nemhauser and A. R. Kan (Eds.). Handbook in Operations Research and Management Science. Vol. 9. Elsevier Science B. V., Amsterdam.

Gibbons, M. R., S. A. Ross, and J. Shanken (1989). A Test of the Efficiency of a given Portfolio. Econometrica, 57, pp. 1121-1152. 
Grinblatt, M. and S. Titman (1987). The Relation between mean-variance efficiency and Arbitrage Pricing. Journal of Business, 60, pp. 97-112

Lehmann, B. N. and D. M. Modest (1988). The Empirical Foundations of the Arbitrage Pricing Theory. Journal of Financial Economics, 21, pp. 213-254.

Mackinlay, A. C. (1987). On Multivariate Tests of the CAMP. Journal of Financial Economics, 18, pp. 341-372.

Muirhead, R. (1982). Aspects of Multivariate Statistical Theory. John Wiley, New York.

Shanken, J. (1986). Testing Portfolio Efficiency when the Zero-Beta Rate is unknown: a Note. The Journal of Finance, 41, pp. 269-276. 